\title{
Design and Prototyping of Teff (ณ६) Row Planter and Fertilizer Applier
}

\author{
Tesfaye Gonite ${ }^{1, ~ *}$, Hiluf Reda ${ }^{2}$ \\ ${ }^{1}$ School of Mechanical and Industrial Engineering, Addis Ababa University Institute of Technology, Addis Ababa University, Addis Ababa, \\ Ethiopia \\ ${ }^{2}$ Mechanical Engineering Department, College of Engineering, Institute of Technology, Debre Berhan University, Debre Birhan, Ethiopia
}

Email address:

teg1621@gmail.com (T. Gonite), hilufr@gmail.com (H. Reda)

${ }^{*}$ Corresponding author

\section{To cite this article:}

Tesfaye Gonite, Hiluf Reda. Design and Prototyping of Teff ( $\mathrm{\Omega}$ ६) Row Planter and Fertilizer Applier. International Journal of Mechanical Engineering and Applications. Vol. 6, No. 4, 2018, pp. 91-97. doi: 10.11648/j.ijmea.20180604.11

Received: July 5, 2018; Accepted: September 1, 2018; Published: September 21, 2018

\begin{abstract}
Teff is one of the most grown crops and a preferable food in Ethiopia. Wholesale prices for Teff are relatively high, making the crop attractive to some producers as a cash crop, production costs are also high, implying fertilizer prices and the labor-intensive nature of the crop. Now a daysteff got attention of international market. But, productivity yields are relatively low (around 1.2 tones/ha) and suffer from high loss rates (25-30\% both before and after harvest). Respective bodies tried to take different actions to improve the productivity of teff. It has been argued recently that low teff productivity is partly caused by the way farmers sow teff seed; broadcasting teff seed by hand using a rate of 25-50 kg per hectare. Researchers approved reducing the seed rate to between 2.5 and $3 \mathrm{~kg}$ per hectare by row planting allows for reduced competition between seedlings and optimal tillering of the teff plants. This study was aimed to design and prototyping of teff row planter and fertilizer applier. It will improve productivity of teff and reduces cost of teff production process. Literature review and visiting of existing teff row planter machines, conceptual and embodiment design procedures, modeling machine components by solid work software, manufacturing the components and assembling of machine in Debre Berhan university manufacturing workshop, testing the applicability of machine on farm were used as methodology. The metering of teff and the locomotion mechanism of the machine has given more emphasis through the design and manufacturing process. The researchers designed ten rows planter. Due to lack of appropriate manufacturing machine and material, actually obtained a machine which can plant six rows in one trip. For better result and applicability, components should produce with appropriate machine and from appropriate material. some shaking mechanism also recommended for better performance.
\end{abstract}

Keywords: Teff, Row Planter, Fertilizer Applier, Designing and Prototyping, Testing

\section{Introduction}

\subsection{Introduction}

From time of the olden days, agriculture remains the backbone of Ethiopia 's economy and still expected to play a dominant role in the years to come. Agriculture employs about $83 \%$ of the total population and $90 \%$ of the total export earnings, $43 \%$ of Gross Domestic Product (GDP) and provides about $70 \%$ of the county's raw material requirement for large and medium scale industries [1]. Hence, the performance of the agricultural sector largely determines the performance of the entire economy of the country [2].
Berhe also wrote as "Teff accounts for about $15 \%$ of all calories consumed in Ethiopia. Furthermore, approximately 6 million households grow teff and it is the dominant cereal crop in over 30 of the 83 high-potential agricultural woredas" [2].

Teff has enormous potential for growth as it has been given very little attention in research (especially plant breeding), development and public support. Tef's scientific name is Eragrostistef and is believed to have originated in Ethiopia Currently, teff is cultivated as a forage crop in countries like Australia, India, Kenya and the Republic of South Africa with limited human consumption in USA. The crop is the second most widely produced and consumed cereal in Ethiopia. 
According to Seyfu (1989) sited [3, 2], Tef has remained an important crop to Ethiopian farmers for several reasons, namely: the price for its grain and straw are higher than other major cereals; the crop performs better than other cereals under moisture stress and waterlogged conditions; its grain can be stored for a long period of time without being attacked by weevils; there is no disease epidemic that has threatened its performance; 'Injera' made of Tef flour is a staple diet of most Ethiopians, while the straw provides a nutritious feed for cattle; finally, the straw is used as a house plastering material. CSA data over the past few years show that Tef ranked first in terms of area coverage (accounting for $28 \%$ of the area) and is second to maize in terms of volume of production among cereals, accounting for about $20 \%$ of the total produce in the category [3]. The average growth rate of Meher (main rainy) season production of Tef over the past few years has been around $11 \%$ per year, according to the CSA. Increased productivity is believed to contribute about $6 \%$ of the growth while about $5 \%$ was attributed to expansion in area cultivated to Tef $[3,4]$.

Tef is likely to remain a favorite crop of the Ethiopian population and the crop is also gaining popularity as a health food in the western world. Studies show that Tef is a gluten free crop, which makes it is suitable for patients with celiac disease $[2,1]$.

However, yields are relatively low (around 1.2 tones/ha) and suffer from high loss rates $(25-30 \%$ both before and after harvest). Furthermore, while wholesale prices for Teff are relatively high, making the crop attractive to some producers as a cash crop, production costs are also high, implying fertilizer prices and the labor intensive nature of the crop [1].

According to BoARD( beuro of agricultural and rural development), Row planting technology was introduced in 2010/2011 at farm level. It has been argued recently that low teff productivity is partly caused by the way farmers sow teff seed. Traditionally, farmers broadcast the seed using a rate of 25-50 kg per hectare [1]. This practice reduces yields because of the uneven distribution of the seeds, higher competition between plants for inputs (water, light and nutrients), and difficult weeding once the plants have matured. As a solution, it has been proposed to reduce seed rates and to plant seed in rows or to transplant seedlings (as is often done for rice, for example). Reducing the seed rate to between 2.5 and $3 \mathrm{~kg}$ per hectare allows for reduced competition between seedlings and optimal tillering of the teff plants. By row planting or transplanting the seeds, land management and especially weeding can also be done more readily and the incidence of lodging is reduced [1].

Previously some works on row planting of teff were done by the farmers as well as researches. Hawassa University, design kit, TECHTRA and others tried to develop teff row planter for smallholder farmers $[5,6,7]$.
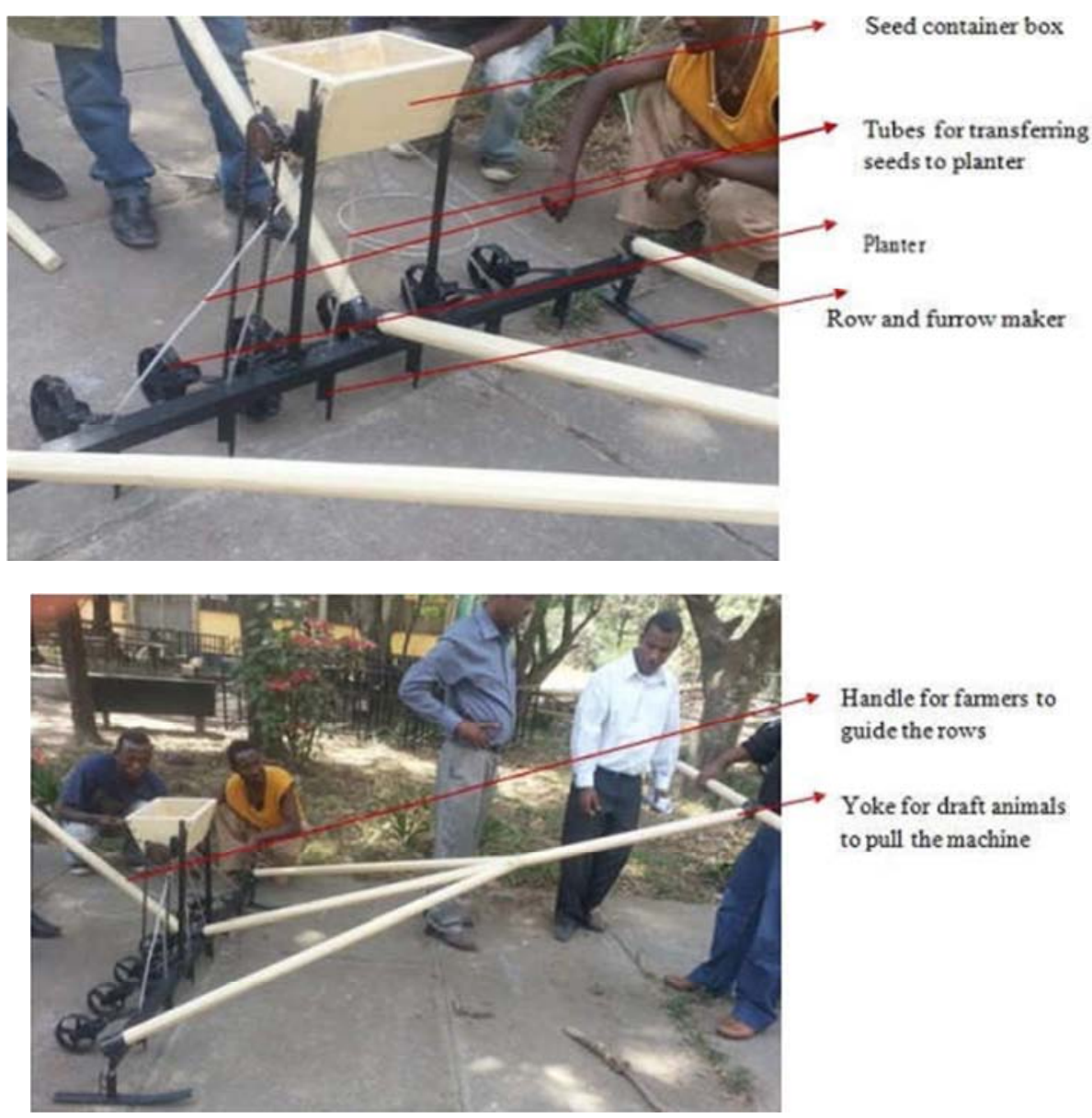

Figure 1. Teff row planter by Hawassa University. 


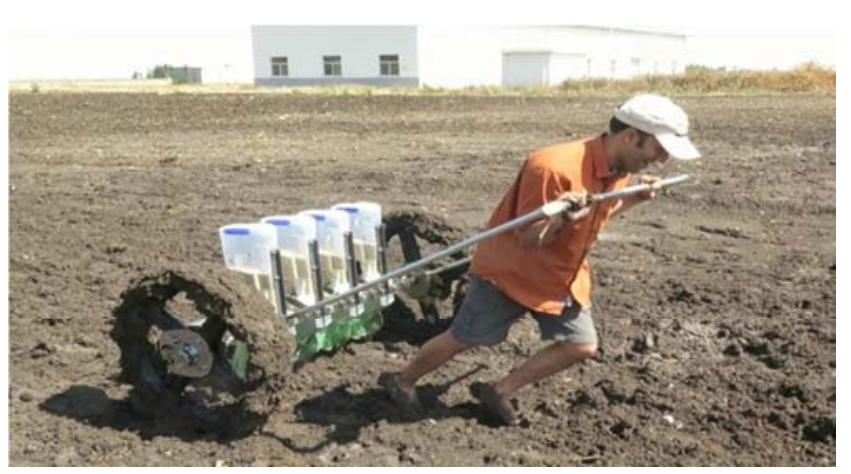

Figure 2. Teff row planter by Design kit.

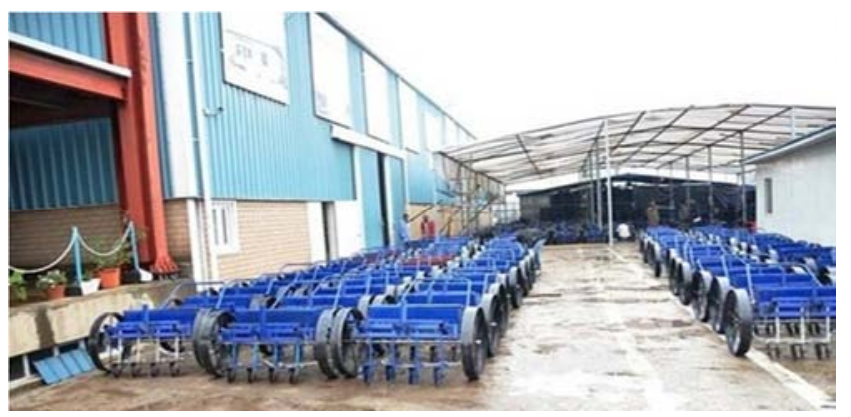

Figure 3. Teff row planter by TECHTRA.

Even though, the problem is not properly solved yet. The researchers believed a lot of investigations must be done in future. This work is done as a result of this driving problem.

\subsection{Statement of the Problem}

In Ethiopia teff is one of the crops that are cultivated widely throughout the country. This practice should support with different technologies in order to improve the productivity of teff. But the farmers still produce using traditional way. They have no raw planter and fertilizer applier. Research on improved teff technologies has received limited international attention mainly because of the crop having only local importance [2]. Due to this, farmers lost their time by planting in row by their hand, they lost seed, human power, and fertilizer $[8,11]$. There is also the conflict between the farmers and agriculture extension professionals during the planting of teff and other crops, because of the above reasons farmers want to plant by the traditional way that is planting without row.

\subsection{Objective of the Study}

\subsubsection{Main Objective}

The main objective of this study was to design and manufacture the prototype of teff row planter and fertilizer applier.

\subsubsection{Specific Objectives}

(1) The objectives of the study are:

(2) To identify the agronomy of the crops

(3) To identify the soil types and their properties

(4) To identify the energy source for the machine
(5) To design the machine components and the whole machine

(6) To manufacture the prototype of the machine

(7) To test the machine on the farm

\subsection{Methodology of Study}

In order to achieve the objective, the researchers used the following strategies.

(1) Literature survey: - books, journals, previous research works to know: basic concepts of row planter and fertilizer applier, properties that have been considered during design of teff raw plants, the previous finding on teff raw planter and fertilizer applier were reviewed.

(2) Visiting: - the selected teff farming areas in North Shoa zone to identify the soil type and property during planting season, and also the agricultural machinery development centers at Combolcha and Awash Melkassa, Adama in Ethiopia are visited.

(3) Analytical analysis: - was used to analyze and determine the input and output of mechanisms that can be used in the machine. The input pushing and pulling force effects in the output (the cam rotation and the controlling of metering valve), the relation of wheel displacement and inter plant distance are calculated

(4) Software modeling: - was used to model the parts and assembly of the machine. working drawing also drawn for manufacturing components

(5) Manufacturing: - components and assembly activities which were manufactured in Debre Birhan university mechanical engineering workshop.

(6) Testing: - the row planter and fertilizer applier was tested at teff planting farm land.

\subsection{Significance of the Study}

It will enhance the habit of row planting.

It will save man power.

It will increase productivity of teff.

It will save seed by avoiding unwanted seed loss.

It will initiate other Ethiopian researchers.

It will used as reference for other studies.

\section{Design and Analysis}

\subsection{Conceptual Design}

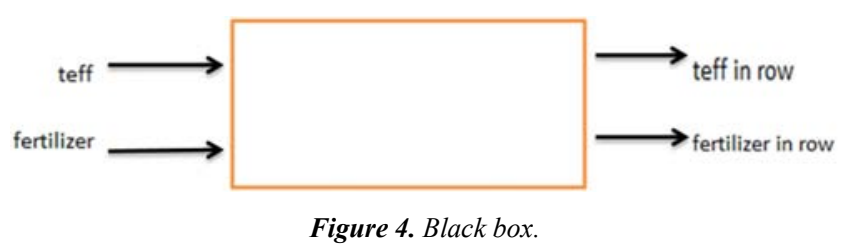

\section{Function structure}

The row planter and fertilizer applier is consists of wheel for locomotion, container for teff and fertilizer, metering of 
teff and fertilizer, shaft to connect the wheels, line/row tracer, covering mechanism and motion translation mechanism

(rotation to translation) from shaft to metering as well as handling.

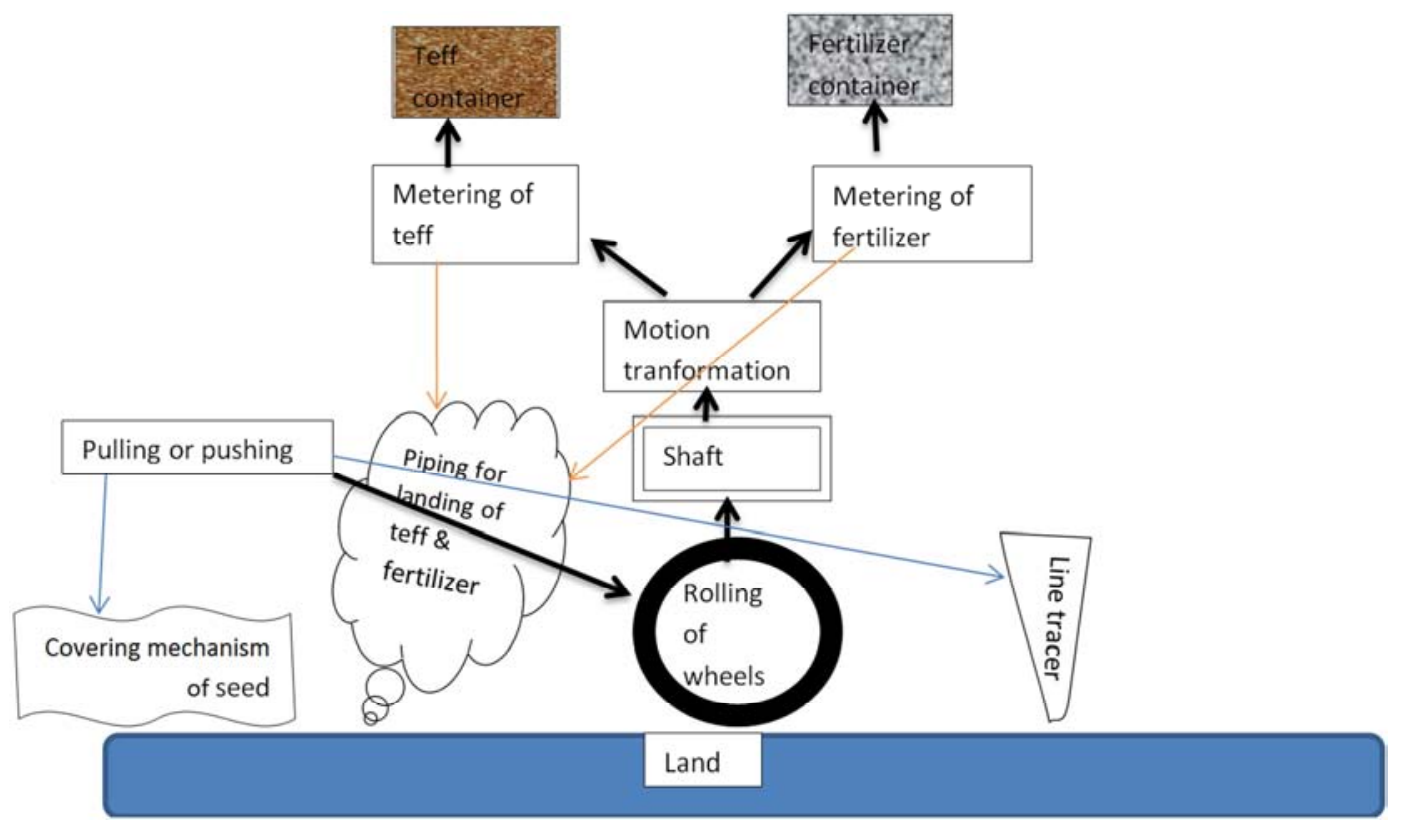

Figure 5. Function structure.

(1) Wheel

Since the planting season for teff is the rainy season, it is expected that there is low friction and strength lacked soil to withstand the load of the machine as well as to suit rotational motion. In some places there is farm with small size stone which affect the motion and the surface of wheel. Therefore, the wheel should be light weight, rough, relatively high diameter and strong enough. The cycle wheel was failed during first trial. It replaced by metal wheel.

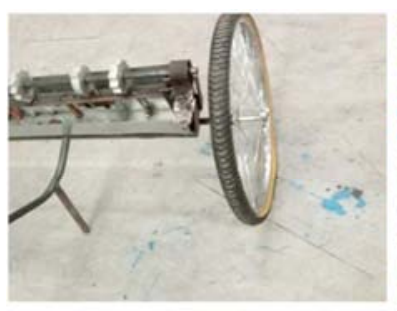

a)

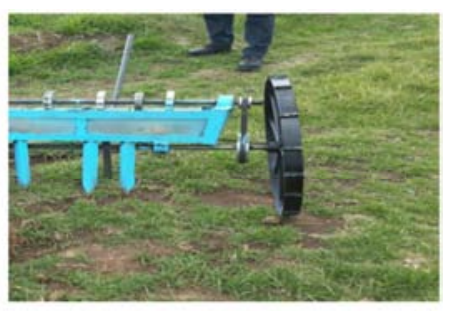

b)
Figure 6. Camera shot a) cycle wheel b) metal wheel.

(2) Shaft

Two shafts, cam shaft and wheel shaft are used. There are twisting and transvers loads on the shaft. It is expected to have high strength. There for hallow shaft is preferable for its low weight and its ability to withstand twisting load than solid one.

(3) Metering valve

Since teff seed is very tiny, it is difficult to count and measure the required amount of seed at required moment. Metering valve is used for controlling the amount of teff and fertilizer to drop at right position. Intermittent motion application is used. It is spring loaded and uniformly actuated by cam on the shaft.
(4) Containers

The containers must be tough, light weight, corrosion resistant, and water proof. Hence it may be plastic or aluminum sheet or galvanized sheet metal. Because of availability and suitability for above properties galvanized sheet metal is used.

(5) Pulling or Pushing Mechanism

The source of motion is either pulling or pushing or both. Therefore, it needs strong handling system. For best use both bulling and pushing components.

\subsection{Embodiment Design}

For the time being the length of the machine is taken as the length of the yoke used by our local farmer i.e around two meters. As shown below in fig.7 according to the Amhar region package for teff 2007 the gap across row is 20 C.M. the distance inter plant is approximately 3 C.M (three plants in10 C.M). Likewise, within fertilizer is 45 C.M and between fertilizers is 40C.M. The seeding depth must be $1 / 8$ to $1 / 4$ inch. Planting deeper than $1 / 2$ inch is likely to result in a complete stand failure $[9,10]$.

\section{fertilizer applying style for teff}

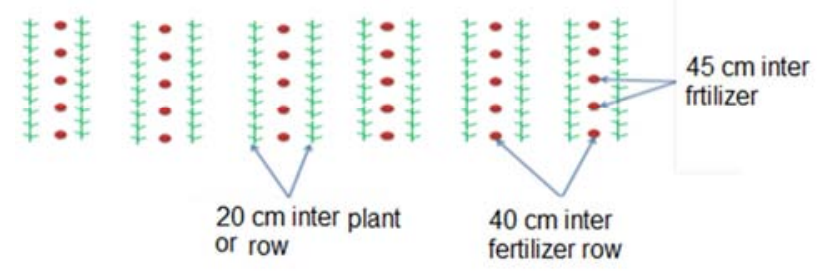

Figure 7. Fertilizer applying style. 


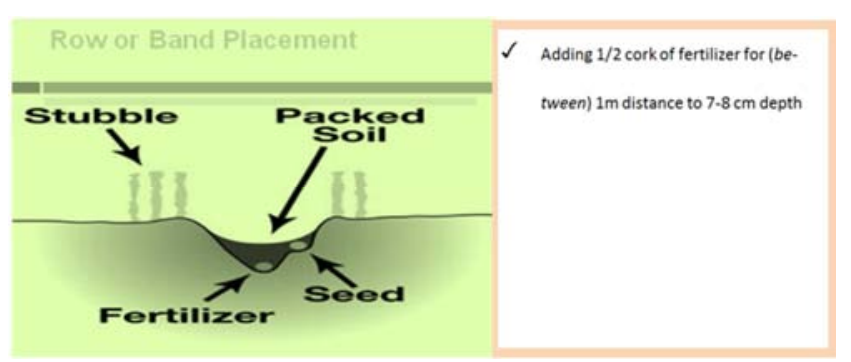

Figure 8. Seed and fertilizer applying style.

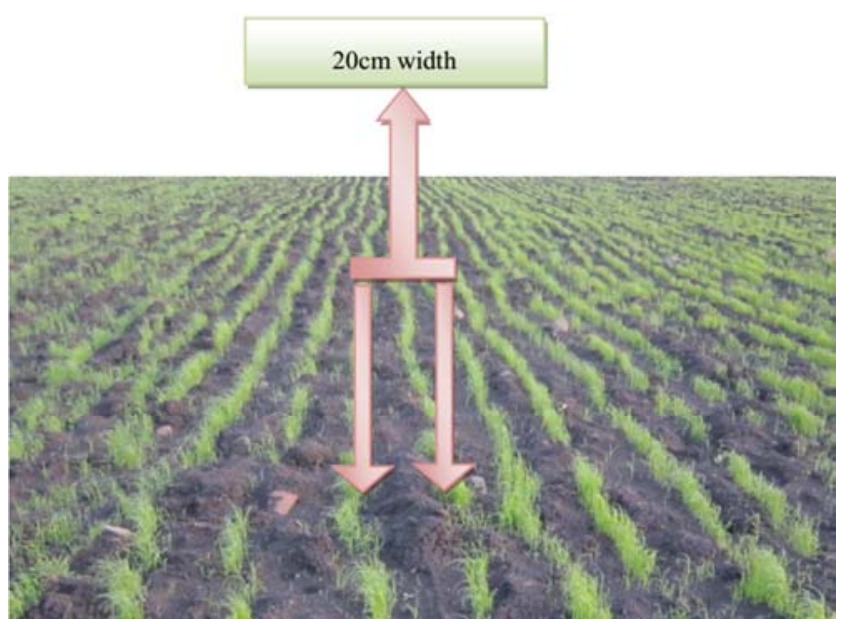

Figure 9. Teff row planting style.

Therefore, ten rows may be planted in one trip. For $100 \mathrm{~m}$ trip it may need 2 minutes. For one hectare 50 trips required. Hence somebody may finish planting in 100 minutes by one machine.

There will be 10 teff row and five fertilizer rows. If the wheel has 63.8 C.M diameters, it will cover $2 \mathrm{M}$ in one rotation. i.e 60 plants have planted. The cam design should consider this fact.

Motion transmition from wheel to cam shaft

The rotational motion of the wheel is transmitted to cam shaft by using two pulleys which are connected by v-belt. The pulleys dimension is in the ratio 1:6, the smaller is on the cam shaft and larger is on the wheel shaft.

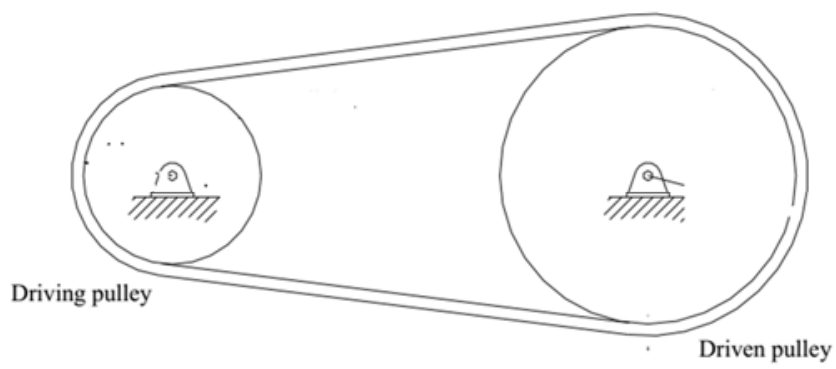

Figure 10. Belt motion transformation.

Metering and cam

There are two different cams those are for teff metering and fertilizer metering actuators. Their design is based on fig.10 and the motion tansmition ratio i.e 1:6 described above. Based on this the cam for teff metering`s actuating had 10 lobs which are equally spaced in circular array at equal radius position. Whereas cam for fertilizer metering's actuating had only one lob.
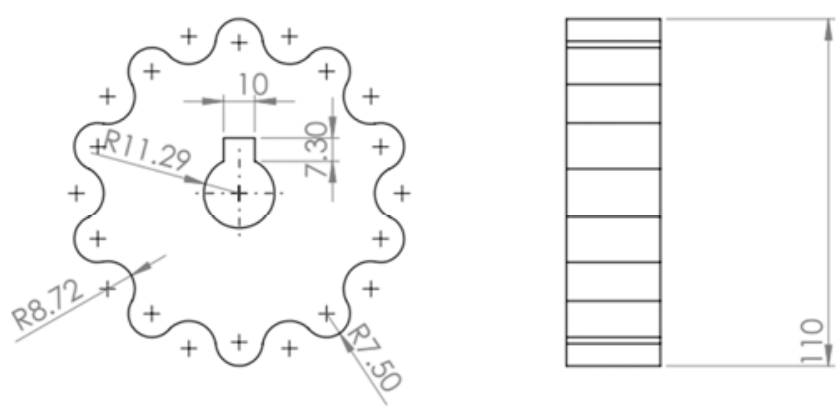

a)

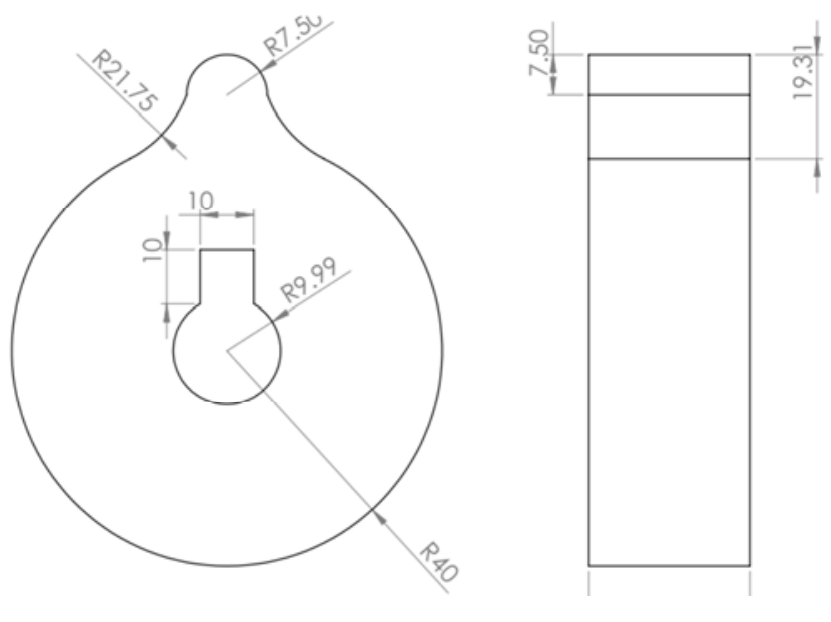

b)

Figure 11. a) teff metering cam b) fertilizer metering cam.

Line tracing

The line tracing component is rigidly attached to the frame at the front of the machine. The space of the tracer is based on fig.9. It used to make line for teff and fertilizer.

Covering method

Covering part of machine is used for cover the teff seed and fertilizer after planting in the line traced by line tracing. the seed and fertilizer should cover by soil in order to protect the seed and fertilizer from water erosion, sunlight, and birds. it also important to make comfort for germination.

\section{Manufacturing and Testing Result}

\subsection{Manufacturing Methods}

Regardless of appropriate machine and materials as per design researchers tried to use the following manufacturing methods:

(1) Milling -cams are produced by milling machine to make the lobs.

(2) Lathe-before machining on milling turning and facing operations are taken place.

(3) Welding -is type of permanent joint. Here it is used for constructing the frame of the row planter and fertilizer 
applier.

(4) Drilling-all holes and circular tubes are produced by drilling.

(5) Shearing- all sheet metals are cut by shearing machine.

(6) Filling and polishing - to get good surface finish and appropriate shaping.

\subsection{Assembly Procedure}

Assemble bearing and pulley on wheel shaft followed by adding two wheels to wheel shaft.

Construct the frame and assemble on 1 through bearing on the wheel shaft.

Construct the teff and fertilizer container and assemble on the frame.

Insert teff and fertilizer metering valve through the holes made on the container respectively.

Mount the bearings for cam shaft on the frame and mount cams on the shaft, then assemble it on frame.

Assemble the tracer and covering mechanisms.

Finally assemble the handle of machine.

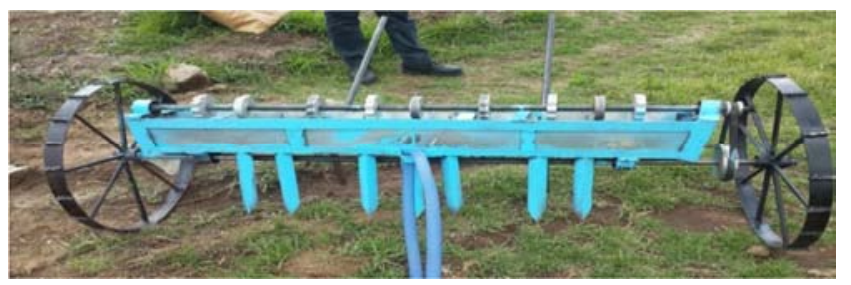

Figure 12. Final assembly phot.

\subsection{Testing}

Testing was taken place on Friday; 30/10/2009 E.C and Monday; 3/11/2009 E.C. During the first testing the motion of the wheel was not transmitted to cam shaft properly. That was because the cycle wheel unable to withstand the load and the wheel shaft was bending. The required corrections on wheel and the shaft taken place and tested for second time. During testing the agriculture college dean and engineering college dean, engineering research and community service coordinator, department coordinators, engineering and agriculture coordinators were available there. During the testing the respective guests suggested valuable comments and appreciations. The researchers also observed the machine needs shaking or vibrating mechanism to have appropriate planting operation.

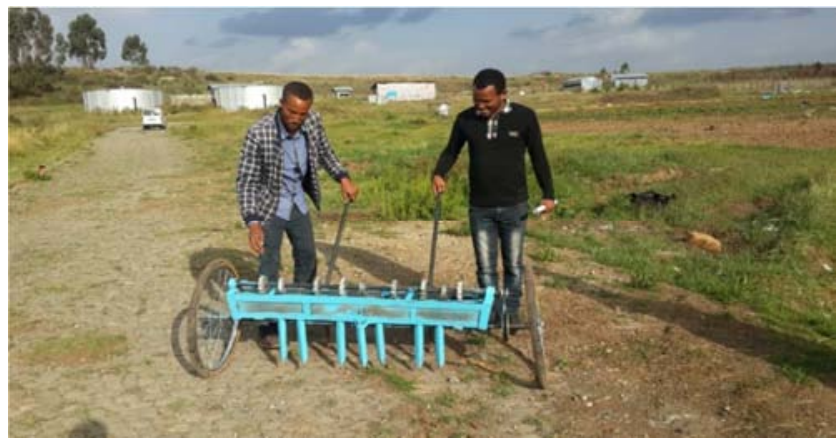

a)

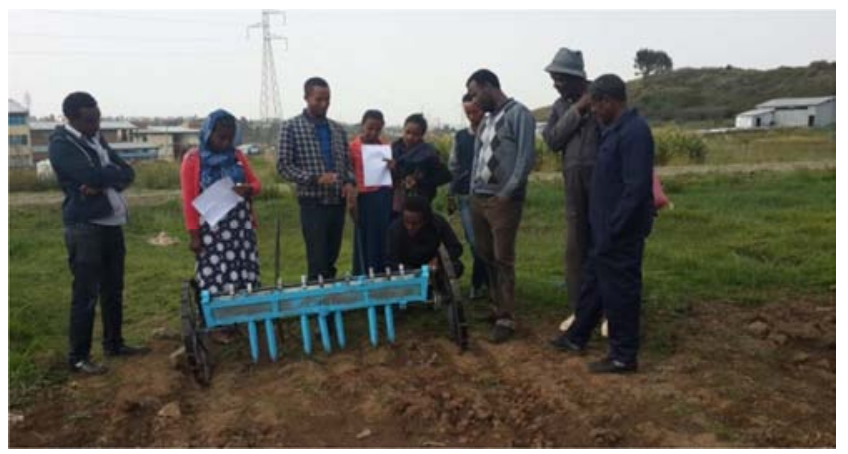

b)

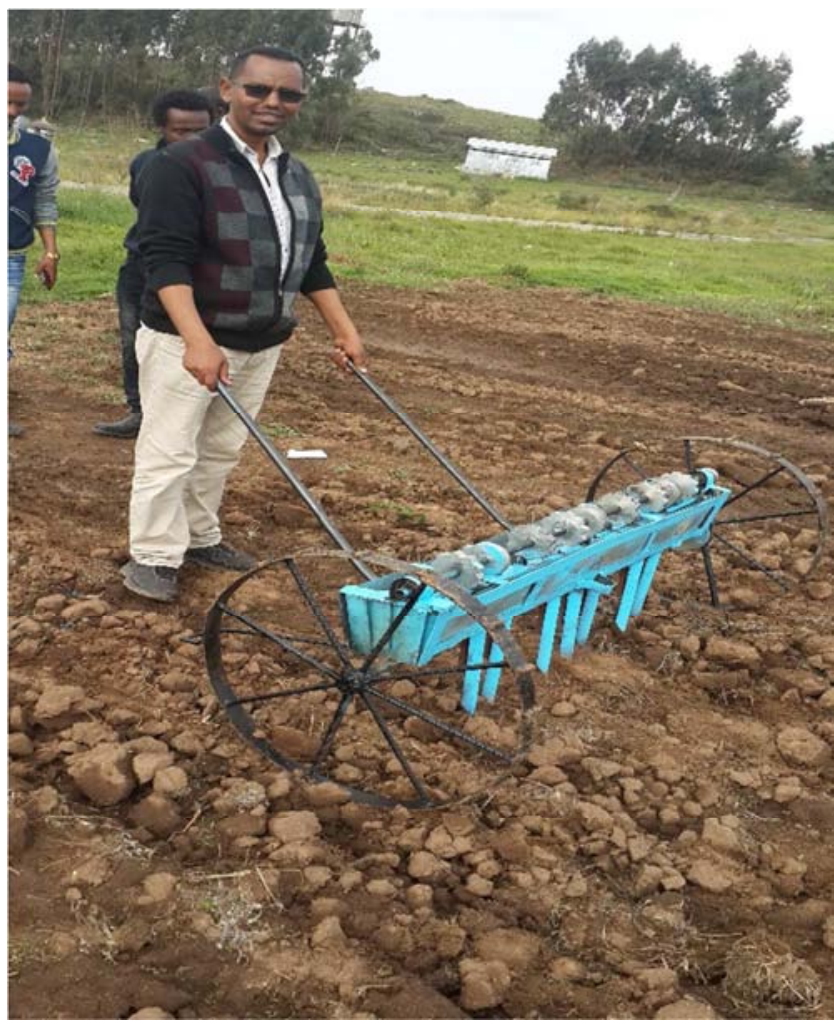

c)

Figure 13. a), b), c) Testing photos. 
Table 1. The estimated cost of machine.

\begin{tabular}{|c|c|c|c|c|c|}
\hline No & List of materials & Quantity & dimensions & Cost (birr) & Remark \\
\hline 1 & Galvanized sheet metal & 1 & $2 \mathrm{~m} \times 2 \mathrm{mX} 1.5 \mathrm{~mm}$ & 500 & \\
\hline 2 & Flat iron & 2 & $40 \times 6000 \times 2.5 \mathrm{~mm}$ & 600 & \\
\hline 3 & Bearing & 4 & Tapered roller Ø25 & 1000 & \\
\hline 4 & $\mathrm{v}$-belt & 1 & B-grade & 100 & \\
\hline 5 & Bolt and nut & 10 & M10x1.5 & 50 & \\
\hline 6 & spring & $500 \mathrm{~mm}$ long & $\varnothing 25 \mathrm{~mm}$ & 200 & \\
\hline 7 & Circular tube & 2 & $(6 \mathrm{mx} 25 \mathrm{~mm} \times 1.5 \mathrm{~mm})$ & 300 & \\
\hline 8 & Angle iron & 2 & $40 \mathrm{~mm} \times 40 \mathrm{~mm} \times 2 \mathrm{~mm}$ & 600 & \\
\hline 9 & Aluminum ingot & 1 & $500 \mathrm{~mm}, \varnothing 150 \mathrm{~mm}$ & 200 & \\
\hline 10 & Manufacturing cost & & & 5000 & \\
\hline Total & 8,550 & & & & \\
\hline
\end{tabular}

\section{Conclusion and Recommendation}

\subsection{Conclusion}

This research work was aimed to design and prototyping of teff row planter and fertilizer applier to solve the problem that facing the farmers. Visiting and experience sharing, literature review, software modeling and manufacturing of the machine were used as methodology. The conceptual, embodiment and detail design of the machine which could plant six rows in one trip was designed. The manufacturing of machine also, done in the mechanical work shop by using the available machines and materials. Finally testing of the machine was taken place at Debre Birhan University, agriculture farming field. The result from testing was close to what expected. It is due to accuracy in manufacturing of parts of machines, and the use of unappropriated materials.

\subsection{Recommendation}

Since this design is the first trial it has some limitations. There for in order to use it in real farm the researchers recommend the following issues.

Some parts of the machine are not appropriate and are not accurate because of lack of appropriate machines and material as per design. There for it is better to manufacture parts by appropriate machines from appropriate materials.

This research came up with six row planting machine. For better productivity it is advisable to manufacture more than twice this machine.

From testing result the shaking/vibrating mechanism is important.

It also expected to design this machine to suit for tractor.

Since it is first design it is also opened for any appropriate modification.

\section{References}

[1] MOA/ATA. (2011). 2011 achivements and plans for 2012. Addis Ababa.

[2] Berhe, Y. (2014). The impact of row planting of teff crop on rural Household income: A case of Tahtay Maychewwereda, Tigrai, Ethiopia . unpublished.

[3] BekabilFufa, e. (2011). Strengthening the Tef Value Chain in Ethiopia. Ethiopian Agricultural Transformation Agency, 11.

[4] Joachim Vandercasteelen, M. D. (2013). Scaling-up adoption of improved technologies: The impact of the promotion of row planting on farmers' teff yields in Ethiopia. BELGIUM: LICOS Centre for Institutions and Economic Performance

[5] Cascap. (2016, January 30). were we work. Retrieved from google: http://www.cascape info/.

[6] Prakash, R. (2017, July 05). Method in action, Rapid prototyping. Retrieved from google: http://www.designkit.org/stories/92.

[7] TECHTRA. (2017, July 05). We are working in the agricultural sector. Retrieved from google: http://www.techtraengineering.com/agriculture.html.

[8] LICOS Discussion Paper Series. (2014). discussion paper 350/2014. Belgium : kuleuven.

[9] Miller, D. D. (2011). teff grass crop overview and forage production guide third eddition . calwrest seeds.

[10] Amhara Regional government agriculturbereou. (2007 E.C, Feb. 27). Teff package. unpublished. Kombolcha, Ethiopia.

[11] Desta, B. G. (June 2014). Assessment of Factors Affecting Farmers' Adoption level of Row Planting Technology and Yield Improvement on the Production of Eragrostis Teff [ZUCC.]: The Case of Minjar Shenkora Woreda, Amhara Region, Ethiopia. unpublished. 